\title{
Determination of the time norms for excavating soil with a mini excavator
}

\author{
Ilyas Galiev*, Ruslan Ibragimov \\ Kazan State University of Architecture and Engineering, 420043, Kazan, Russia
}

\begin{abstract}
Since 2010, there has been a growing trend in the market for mini-excavators from various manufacturers. The range of manufactured equipment is increasing, as well as the technological capabilities of construction equipment are growing. At the same time, in the modern standards of Russia are no figures on the complexity of soil excavation with this type of technology.

The article shows the timing of soil excavation using the example of a mini-excavator with a bucket volume of $0.03-0.04 \mathrm{~m}^{3}$. The object of the study is the amount of time the mini-excavator works on II group of soils. The timekeeping method is used to determine the operating time of a miniexcavator with a bucket volume of 0.03 and $0.04 \mathrm{~m}^{3}$. It is experimentally obtained that the norm of time for operation of a mini-excavator with a bucket volume of $0.03 \mathrm{~m}^{3}$ is 5.82 mach *hours, and for a bucket volume of $0.04 \mathrm{~m}^{3}$ is 5.37 mach*hour.
\end{abstract}

\section{Introduction}

Despite the versatility of hand tools, at present the tendency to facilitate human labor prevails, more and more technological processes are being replaced by mechanized or automated tools. In recent years, there have been changes in this vein during work on the development and leveling of soils in confined conditions, when more and more small-sized equipment is used, such as mini-excavators, dumpers, mini-loaders, etc. As for miniexcavators, with their appearance and improvement, their size classes are becoming smaller, there is a process of expanding the functional and maneuverable capabilities of excavators, such as additional rotation of the boom about the vertical axis at the point of support on the platform, the absence of a rear extension of the platform, changing the track of the tracked cart for the possibility of driving through doorways, expansion of attachments, etc. In addition, if until recently compact earth-moving machines were only imported, then today the production of small-sized equipment is being established in Russia. There are developments and started production at such plants as " Plant of

\footnotetext{
*Corresponding author: galiev.ih@gmail.com
} 
construction and drilling equipment "Strong" in the city of Chelyabinsk, models of excavators "Strong MS 1500" or "Strong MS 2000"; the enterprise of JSC "Ural design Bureau of transport engineering" in the city of Nizhny Tagil, mini excavator EO-1121, etc. [1-3].

However, when determining the labor costs for earthworks using mini-excavators in the Russian estimate rationing, certain gaps were revealed associated with the lack of regulatory documents for assessing the cost of work. There are no standards in the applicable regulatory framework Federal unit prices (FER), based on which estimate forms are compiled for many types of construction, repair, installation and other work, State elemental estimate standards (GESN) is a collections of state element estimate standards for construction and special construction works, Federal estimated prices for materials, products, structures and equipment used in construction FSSC 81-01-2001, for the operation of mini excavators with a bucket volume of less than $0.15 \mathrm{~m}^{3}$ [4].

An attempt is made to use computer modeling to determine the norms and duration of the operation of mini excavators in the article [5]. Unfortunately, this work has a narrow direction of research, and the results of the work cannot be applied in the realities of modern large-scale construction [6-8]. Therefore, this issue remains open and requires scientific and practical research.

The purpose of this work: determination of the operating time of mini excavators with a bucket volume of $0.03-0.04 \mathrm{~m}^{3}$ for excavation of soil.

\section{Materials and methods}

To determine the norms of operating time of a mini-excavator for excavating a grant, the timekeeping method was used in this issue.

The timekeeping method is a method of studying the time spent by fixing and measuring the duration of actions performed.

Determination of machine time norms includes the following stages: design of the process normal; determination of the estimated productivity of machines for 1 hour of continuous operation; determination of the amount of regulated breaks in the operation of machines; calculation of the composition of workers; determination of the full value of the norm.

Mini excavators from Wacker Neuson 803 with a bucket volume of $0.03 \mathrm{~m}^{3}$ and JCB 8018 with a bucket volume of $0.04 \mathrm{~m}^{3}$ were taken as the object of the study (Fig. 1).

Subject of research: determination of the length of time for excavation of the soil with a mini-excavator by the timekeeping method.
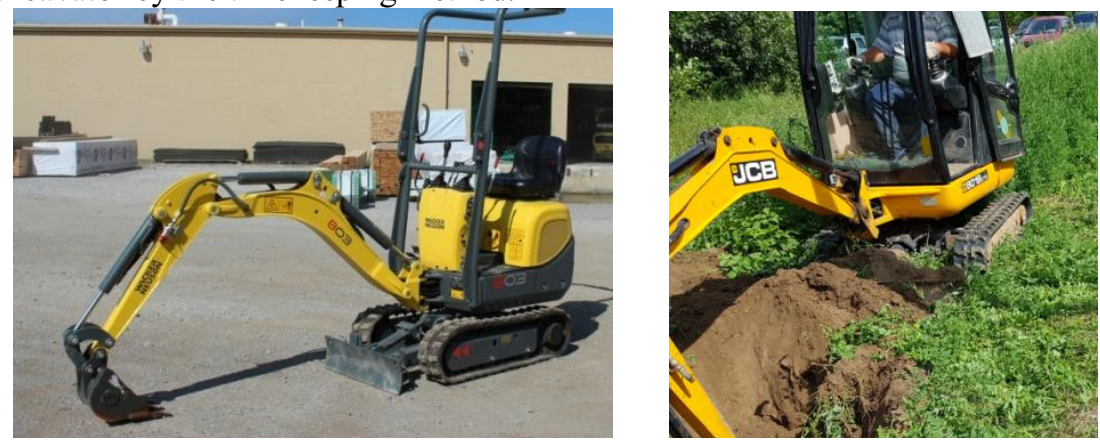

Fig. 1.Mini excavators Wacker Neuson 803 and JCB 8018

The diagram (Fig. 2) shows an analysis of the time of using construction machines for the purpose of standardization. 


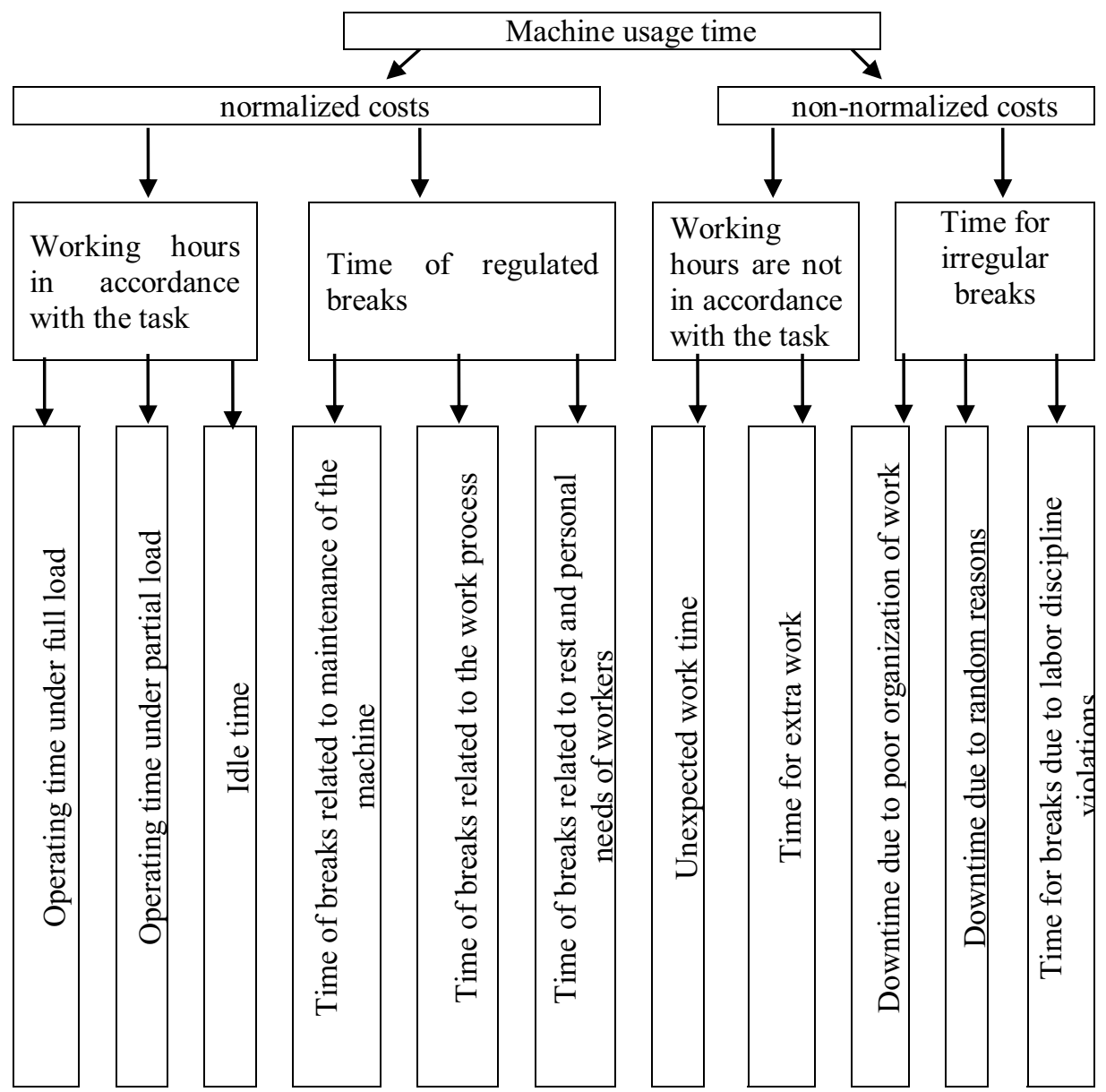

Fig.2. Scheme for analyzing the time of use of construction machinery for rationing purposes

Group I and II soils were accepted for research in accordance with the Russian soil classification. The types of soils and their characteristics are shown in table 1.

Table1. Characteristics of soils of groups I and II

\begin{tabular}{|l|c|}
\hline \multicolumn{1}{|c|}{ Soil } & Group \\
\hline $\begin{array}{l}\text { gravel sand, large and medium-sized granules with a particle } \\
\text { content smaller than } 0.05 \mathrm{~mm} \text { to } 2 \%\end{array}$ & I \\
\cline { 1 - 1 } $\begin{array}{l}\text { gravel sand, large and medium-sized granules with a particle } \\
\text { content smaller than } 0.05 \mathrm{~mm} \text { to } 15 \%\end{array}$ & \multirow{2}{*}{ II } \\
\cline { 1 - 1 } fine sand, with a particle content smaller than $0.05 \mathrm{~mm}$ to $15 \%$ & \\
\hline Light large sandy loam &
\end{tabular}

\section{Results}

In Europe, the basis for the classification of small-sized equipment is the volume of the bucket and the weight of the equipment [9-12]. In the UK, small excavators are divided into 3 categories: micro, mini and super mini. Standard mini-excavators weigh $0.7-5$ tons, mini- 
excavators, in turn, are divided into 3 main groups: weighing up to 2 tons, 2-3.5 tons and over 3.5 tons. [13-16].

In Japan, mini excavators are classified according to bucket volume [17-23].

Some excavator models are summarized in table. 2 .

Table 2. Specifications of some models of mini excavators

\begin{tabular}{c|c|c|c|c}
\hline Characteristic & $\begin{array}{c}\text { STRONG MS } \\
2000\end{array}$ & $\begin{array}{c}\text { Kubota } \\
\text { KX016-4 }\end{array}$ & $\begin{array}{c}\text { JCB } \\
8018 \mathrm{CTS}\end{array}$ & $\begin{array}{c}803 \text { Wacker } \\
\text { Neuson }\end{array}$ \\
\hline Generalform & 0.01 & 0.035 & 0.042 & 0.04 \\
\hline $\begin{array}{c}\text { Standard } \\
\text { bucket } \\
\text { volume, }{ }^{3}\end{array}$ & 850 & 1565 & 1662 & 1016 \\
\hline $\begin{array}{c}\text { Weight, } \mathrm{kg} \\
\text { kngine power, } \\
\mathrm{kW}\end{array}$ & 17.5 & 16 & 14.2 & 9.9 \\
\hline $\begin{array}{c}\text { Digging depth, } \\
\mathrm{m}\end{array}$ & 2.4 & - & 2.044 & 1.731 \\
\hline $\begin{array}{c}\text { Unloading } \\
\text { height, } \mathrm{m}\end{array}$ & 2.4 & 2.29 & 2.501 & 2.012 \\
\hline $\begin{array}{c}\text { The overcome } \\
\text { slope, degrees }\end{array}$ & 30 & - & 35 & - \\
\hline $\begin{array}{c}\text { Maximum } \\
\text { digging force, } \\
\mathrm{kH}\end{array}$ & 8.6 & 12.7 & 16.2 & 4.5 \\
\hline $\begin{array}{c}\text { Productivity } \\
\text { per hour, } \mathrm{m}^{3}\end{array}$ & 3 & - & 2.8 & - \\
\hline
\end{tabular}

In the Russian Federation, an official detailed classification of mini-excavators has not been introduced, since there are no time norms and prices for the use of small-sized equipment. At the same time, the rationing of earthworks begins with excavators with a bucket volume of more than $0.15 \mathrm{~m}^{3}$, the term mini-excavator does not occur.

As part of the study, it is proposed to introduce a classification with a mini-excavator according to the following main characteristics:

- bucket volume $\left(\mathrm{m}^{3}\right)$; excavator weight $(\mathrm{kg})$; engine power $(\mathrm{kW})$; digging depth $(\mathrm{m})$; unloading height $(\mathrm{m})$.

In addition to the main ones, additional characteristics can also be distinguished, such as platform extension, track gauge adjustment, productivity in 1 hour, mechanism for extending the wheels of the caterpillars, turning the boom in a vertical plane at the base etc.

The study was carried out for mini-excavators with a mass of no more than $1600 \mathrm{~kg}$, a bucket volume of 0.04-0.045 $\mathrm{m}^{3}$ using the example of equipment of the JCB 8018 CTS and Wacker Neuson 803 models when working in open areas when developing sandy loam soils (group II) to spoil pumping ( without loading).

Upon observation, it was found that the continuous digging process with the JCB 8018 CTS excavator for the soil of the II group lasted 41 minutes, after which the driver needed to rest for 12 minutes. During the observation cycle, according to the measurement results, $\mathrm{V}=16.45 \mathrm{~m}^{3}$ of soil was dug, which corresponds to the average speed of excavation of the 
developed soil of an undisturbed structure of $0.401 \mathrm{~m}^{3} / \mathrm{min}$. in continuous operation and $0.310 \mathrm{~m}^{3} / \mathrm{min}$ in intermittent operation. At this stage of the experiment, two periods of excavator operation were allocated: the time of digging and the time of technological or other break. If we compare in the first approximation with the prices for $100 \mathrm{~m}^{3}$ of soil, we get:

$$
T=t_{1}+t_{2}, \min
$$

$T_{1}=t_{1}+t_{2}=41+12=53 \mathrm{~min}$.

That is, it took 53 minutes to excavate $16.45 \mathrm{~m}^{3}$ of soil of the II group.

The time norm for excavation of soil with a volume of $100 \mathrm{~m}^{3}$ will be:

$$
T_{\text {norm }}=100 / V^{*} T / 60 \text {, machine } * \text { hour }
$$

$T_{\text {norm }}=100 / V^{*} T / 60=100 / 16.45 * 53 / 60=5.37$ machine $*$ hour

In the process of performing work on the object under study, we carried out measurements by the timekeeping method to clarify labor costs when using a miniexcavator. In order to establish the reliability of the results, 10 measurements of identical soil development cycles of group II were carried out (Table 3).

\begin{tabular}{|c|c|c|c|c|c|c|}
\hline Process names & Start & End & Start & End & Start & End \\
\hline bucket filling & $\begin{array}{l}\overline{-} \\
-\end{array}$ & $\frac{5}{2}$ & $\begin{array}{l}\bar{z} \\
-\end{array}$ & $\frac{2}{2}$ & $\begin{array}{l}\overline{-} \\
-\end{array}$ & $\frac{1}{1}$ \\
\hline $\begin{array}{l}\text { lifting and swinging the } \\
\text { boom }\end{array}$ & $\bar{z}$ & $\frac{4}{3}$ & $\begin{array}{l}\overline{-}- \\
\end{array}$ & $\frac{3}{4}$ & $\overline{-}$ & $\frac{4}{3}$ \\
\hline unloading of soil & $\begin{array}{l}\bar{z} \\
-\end{array}$ & $\frac{2}{2}$ & $\begin{array}{l}- \\
-\end{array}$ & $\frac{1}{1}$ & $\begin{array}{l}\bar{z} \\
-\end{array}$ & $\frac{1}{1}$ \\
\hline bucket shaking & $\begin{array}{l}\overline{-} \\
-\end{array}$ & $\underline{0}$ & $\begin{array}{l}= \\
-\end{array}$ & $\frac{1}{0}$ & $\begin{array}{l}z \\
-\end{array}$ & $\frac{1}{0}$ \\
\hline dump soil correction & $\begin{array}{l}z \\
-\end{array}$ & $\frac{3}{0}$ & $\begin{array}{l}z \\
-\end{array}$ & $\begin{array}{l}\overline{-} \\
-\end{array}$ & $\begin{array}{l}\overline{-} \\
-\end{array}$ & $\frac{3}{0}$ \\
\hline $\begin{array}{l}\text { returning the bucket to its } \\
\text { original position }\end{array}$ & $\begin{array}{l}\bar{z} \\
-\end{array}$ & $\frac{6}{4}$ & $\begin{array}{l}\overline{-} \\
-\end{array}$ & $\frac{11}{3}$ & $\begin{array}{l}\bar{z} \\
-\end{array}$ & $\frac{10}{5}$ \\
\hline $\begin{array}{c}\text { Soil preparation for } \\
\text { development (loosening, } \\
\text { pulling) }\end{array}$ & $\begin{array}{l}\overline{-} \\
-\end{array}$ & $\frac{11}{0}$ & $\begin{array}{l}z \\
-\end{array}$ & $\underline{60}$ & $\begin{array}{l}z \\
-\end{array}$ & $\frac{12}{10}$ \\
\hline Move to a new position & $\begin{array}{l}z \\
-\end{array}$ & $=$ & $\overline{-}$ & $\frac{0}{4}$ & $\begin{array}{l}\overline{-} \\
-\end{array}$ & $\begin{array}{l}\overline{-} \\
-\end{array}$ \\
\hline
\end{tabular}

Table 3. Timing during operation of a mini-excavator with a bucket volume of 0.04 and $0.03 \mathrm{~m}^{3}$

Note: 1) cycle times are in seconds; 2) in the numerator the results are given for an excavator with a bucket volume of $0.03 \mathrm{~m}^{3}$, in the denominator $-0.04 \mathrm{~m}^{3}$.

Upon observation, it was established that the continuous digging process with the Wacker Neuson 803 excavator for the soil of the II group lasted for 24 minutes, after which the driver needed a break for 7 minutes. During the observation cycle, based on the results of measurements, $\mathrm{V}=8.87 \mathrm{~m}^{3}$ of soil was dug, which corresponds to the average excavation speed of the developed soil of the undisturbed structure of $0.370 \mathrm{~m}^{3} / \mathrm{min}$. during continuous operation, and $0.286 \mathrm{~m}^{3} /$ min during intermittent operation. When compared in a first approximation with unit prices per $100 \mathrm{~m}^{3}$ of soil, we get:

$$
T_{2}=t_{1}+t_{2}=24+7=31 \text { min. }
$$

That is, 53 minutes were required for excavation of $8.87 \mathrm{~m}^{3}$ of soil of group II.

The time norm for excavation of soil with a volume of $100 \mathrm{~m}^{3}$ will be: 


$$
T_{\text {norm } 2}=100 / V^{*} T / 60=100 / 8,87 * 31 / 60=5.82 \text { machine } * \text { hour }
$$

The excavation process was divided into the following stages in the cycle: filling the bucket with soil, lifting and turning the boom, unloading the soil, shaking the bucket, adjusting the soil in the dump, returning the bucket to its original position, preparing the soil for digging (loosening, pulling), moving to a new position. The cycle repeats itself.

Based on the data in table. 3, it was found that the development of $100 \mathrm{~m}^{3}$ of soil of group II requires 5.82 mash $* h$ for an excavator with a bucket volume of $0.03 \mathrm{~m}^{3}$, and 5.37 mash * $\mathrm{h}$ with a bucket volume of $0.04 \mathrm{~m}^{3}$.

In the estimated rationing in force in Russia, there are no indicators of the norms of time for the operation of excavators with a bucket volume of less than $0.25 \mathrm{~m}^{3}$. Therefore, an extrapolated dependence of the operation of excavators with different volumes of the working bucket is built. For excavators with a bucket volume of 0.03 and $0.04 \mathrm{~m}^{3}$, the data in Fig. 3 were obtained experimentally, the remaining points - according to the estimated norms of Russia.

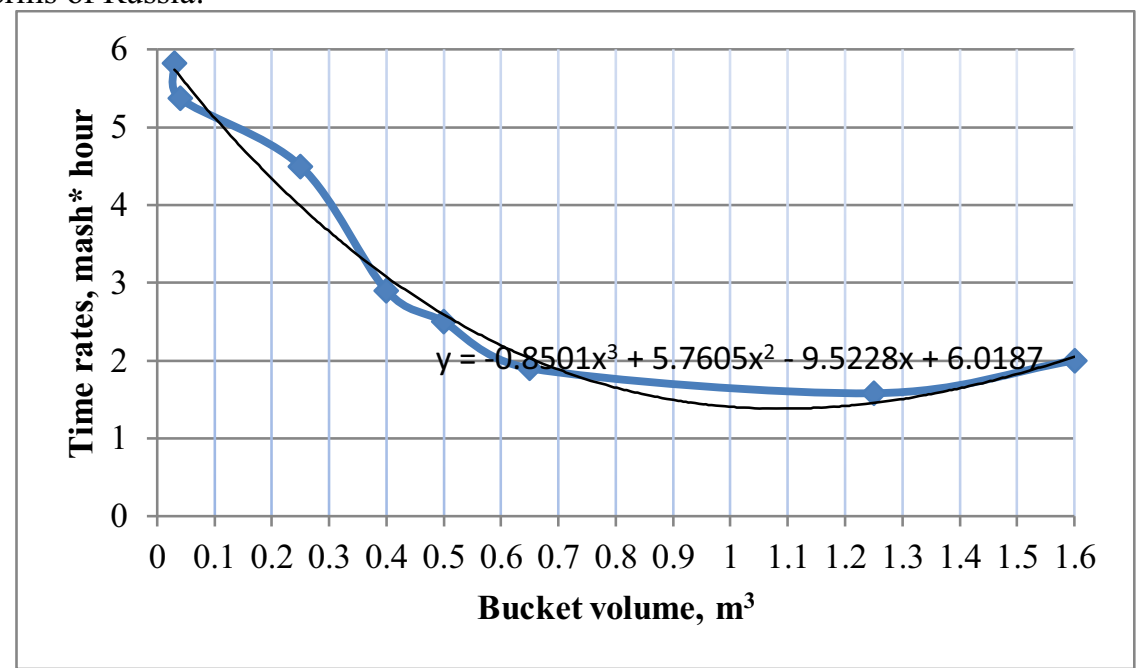

Fig.3. The graph of the dependence of the excavator bucket volume on the time norm

Theoretically, the operating time for a mini-excavator with a bucket volume of $0.03 \mathrm{~m}^{3}$ is 7.28 mash * hours, and for a bucket volume of $0.04 \mathrm{~m}^{3}$ it is 7.12 mash* hours.

It was experimentally obtained that the standard time for a mini-excavator with a bucket volume of $0.03 \mathrm{~m}^{3}$ is 5.82 mash * hours, and for a bucket volume of $0.04 \mathrm{~m}^{3}$ it is 5.37 mash * hours.

Fischer's adequacy was 0.9783 , which indicates a high convergence of results.

\section{Discussion}

1. A classification of mini-excavators according to the following criteria is proposed: bucket volume, $\mathrm{m}^{3}$; excavator weight, $\mathrm{kg}$; engine power $(\mathrm{kW}, \mathrm{hp})$; digging depth $(\mathrm{m})$; unloading height $(\mathrm{m})$.

2. By the method of timekeeping, the norms of operating time of a mini-excavator with a bucket volume of 0.03 and $0.04 \mathrm{~m}^{3}$ were determined. It was experimentally obtained that the standard time for a mini-excavator with a bucket volume of $0.03 \mathrm{~m}^{3}$ is 5.82 mash * hours, and for a bucket volume of $0.04 \mathrm{~m} 3 \mathrm{~m}^{3}$ it is 5.37 mash * hours. 


\section{References}

1. C. Yengst, Mini excavator sales slowly recovering, 2011.

2. Amol Phoke, Priyanka Khandelwal, Onkar Sumant, Mini Excavators Market by Capacity (Less Than 4 Tons and More Than 4 Tons) and End-User Industry (Landscaping \& Construction, Agriculture, and Others), Global Opportunity Analysis and Industry Forecast, 2020-2027.

3. C.R. Yengst, Mini excavators wounded by housing market, 2007.

4. Hannes Wind, Anton Renner, Frank A. Bender, Oliver Sawodny, Trajectory Generation for a Hydraulic Mini Excavator using Nonlinear Model Predictive, Conference: 2020 IEEE International Conference on Industrial Technology (ICIT). Control. 2020. DOI: $10.1109 /$ ICIT45562.2020.9067227.

5. Frank A. Bender, Simon Göltz, Thomas Braunl, Oliver Sawodny, Modeling and OffsetFree Model Predictive Control of a Hydraulic Mini Excavator, IEEE Transactions on Automation Science and Engineering PP(99):1-13. May 2017. DOI: 10.1109/TASE.2017.2700407.

6. P. Alkiviadis, Protection and sustainable development of traditional settlements in the context of tourism development and promotion of employment: values of yesterday, today and tomorrow, V International Scientific - Practical Conference: Cultural heritage in 21st century, Kazan, Proceedings, 11-19 (2017).

7. Petr Prochazka, Ivo Pazdera, Radoslav Cipin, Jan Knobloch, Battery Powered MiniExcavator, ECS Transactions, 87(1) 343-347 (2018). DOI: 10.1149/08701.0343ecst

8. Ruqi Ding, Junhui Zhang, Bing Xu, Min Cheng, Programmable hydraulic control technique in construction machinery: Status, challenges and countermeasures, Automation in Construction, 172-192 (2018). doi.org/10.1016/j.autcon.2018.08.001.

9. Cao et al. / Science of the Total Environment 635 (2018) 112-119.

10. D.Q. Truong, J. Marco, D. Greenwood, L. Harper, D.G. Corrochano, J.I. Yoon, Challenges of micro/mild hybridisation for construction machinery andapplicability in UK, Renewable and Sustainable Energy Reviews, 91 301-320302 (2018).

11. David J. Edwards, Gary D. Holt, Mini-excavator safety: toward innovative stability testing, procurement, and manufacture, Journal of Construction Engineering and Management, 137(12), 1125-1133 (2011).

12. Dongik Suna et al. Sensor-based straight-line control of the end-point of a typical retrofitted hydraulic excavator. Automation in Construction. https://doi.org/10.1016/j.autcon.2020.103385

13. Kyoung Kwan, Ahna Nguyen, Huynh Thai, Design of a robust force controller for the new mini motion package using quantitative feedback theory, Mechatronics, 17 (10), 542-550 (2007). https://doi.org/10.1016/j.mechatronics.2007.07.011

14. Andrea Bedottia et al, Energy saving solutions for a hydraulic excavator, Energy Procedia, 126, 1099-1106 (2017). https://doi.org/10.1016/j.egypro.2017.08.255

15. S. Zhang et al., The effects of control methods on energy efficiency and position tracking of an electro-hydraulic excavator equipped with zonal hydraulics, Automation in Construction 100 129-144 (2019).

16. H. Feng et al., Robotic excavator trajectory control using an improved GA based PID controller, Mechanical Systems and Signal Processing, 105 153-168 (2018).

17. S.-U. Lee, P. Hun Chang, Control of a heavy-duty robotic excavator using time delay control with integral sliding surface, Control Engineering Practice, 10 697-711 (2002). 
18. A. David Bradley et al., Artificial intelligence in the control and operation of construction plant - the autonomous robot excavator, Automation in Construction, 2 (3), 217-228 (1993).

19. Andrea Bedotti et al., Modelling and energy comparison of system layouts for a hydraulic excavator, Energy Procedia, 148 26-33 (2018).

20. E. Budny et al., Load-independent control of a hydraulic excavator, Automation in Construction, 12 245-254 (2003).

21. R.A. Ibragimov, E.V. Korolev, T.R. Deberdeev, V.V. Leksin, D.B. Solovev, Energy parameters of the binder during activation in the vortex layer apparatus, Materials Science Forum, 945 98-103 (2018).

22. R.A. Ibragimov, R.R. Bogdanov, The influence of a complex modifying agent on the hydration and structure formation of self-compacting concrete, ZKG International, 70 (4) 44-49 (2017).

23. V. Stroganov, E. Sagadeev, R. Ibragimov, L. Potapova, Mechanical activation effect on the biostability of modified cement compositions, Construction and Building Materials, 246, 118506 (2020). 